\title{
A dynamic macroscopic parking pricing and decision model
}

\section{Working Paper}

Author(s):

Jakob, Manuel (D); Menendez, Monica; Cao, Jin

Publication date:

2017

Permanent link:

https://doi.org/10.3929/ethz-b-000210326

Rights / license:

In Copyright - Non-Commercial Use Permitted

Originally published in:

SVT Working Papers 


\title{
A dynamic macroscopic parking pricing and decision model
}

\author{
Manuel Jakob ${ }^{1}$, Monica Menendez, Jin Cao \\ Institute for Transport Planning and Systems, ETH Zurich, 8093 Zurich, Switzerland
}

\begin{abstract}
Responsive pricing has been gaining attention in recent research, but its interdependency with searching-for-parking traffic remains still unclear. In this paper, a dynamic macroscopic parking pricing model is developed to maximize the revenue for a city, while simultaneously minimizing the total cruising time on the network. The methodology proposes new parking pricing formulations, and embeds them into a dynamic macroscopic urban traffic and parking model to better replicate reality.

The proposed responsive pricing scheme takes the parking search phenomenon into consideration. This means that the parking fee also changes in response to the number of searching vehicles, in addition to changes in response to the parking occupancy. An optimization model is formulated to maximize the parking pricing revenue to the highest level, such that the cost of paying the current parking fee remains smaller than the cost of keep on searching to obtain a lower parking fee (i.e., so the total cruising time on the network is minimized). To do so, multiple user groups are considered with respect to their value of time. Several cost variables are then taken into consideration, including the predicted parking cost at a future time, and the penalty cost for the past cruising time.

Compared to most literature, this macroscopic pricing model has rather low data requirements, mostly related to average values and probability distributions at the network level. Hence, this macroscopic pricing approach saves on data collection efforts and reduces the computational costs significantly. Moreover, the model can be easily solved with a simple numerical solver without the use of complex simulation software.

The pricing policy's impacts on the searching-for-parking traffic (cruising), the congestion in the network (traffic performance), the total driven distance (environmental conditions), and the revenue created by parking fees, are illustrated in a case study of an area within the city of Zurich, Switzerland. Results show that the pricing scheme is not only feasible, but successful at improving these different metrics. The model also provides a preliminary idea for city councils regarding an optimal parking pricing policy resulting in financial revenues that can be obtained without having a significant negative effect on traffic performance and environmental conditions in the short-term.
\end{abstract}

Keywords: Dynamic macroscopic parking pricing model; Responsive parking pricing; Parking-related traffic state; Cruising-for-parking.

\footnotetext{
${ }^{1}$ Corresponding author. Tel.: +49 15110831 281; fax: +41 446331057.

E-mail address: manuel.jakob@ivt.baug.ethz.ch
} 


\section{Introduction}

In nearly all major cities, parking pricing policies can lead to significant changes on the performance of a transportation network. Short-term pricing strategies, for example, can have an influence on the performance of both the urban parking and traffic systems, e.g., parking pricing can affect the parking availability, the congestion and traffic performance, or the traffic composition in the network. In this research, we propose a dynamic macroscopic parking pricing model which analyzes the interdependency between responsive parking pricing and searching-forparking traffic, while maximizing the parking pricing revenue and simultaneously minimizing the total cruising time on the network. It includes several cost variables (e.g., predicted parking cost at a future time, penalty cost for the past cruising time) in order to better replicate realistic conditions and determine the influence of parking pricing on cruising vehicles. This parking pricing scheme can then be compared to existing pricing methodologies.

In general, attractive parking fee schemes are often based on empirical or modelling approaches. Empirical approaches usually collect data by using parking meters for on-street parking spaces, e.g., SFpark (2009), Xerox ${ }^{\circledR}$ (implemented in Los Angeles's LA ExpressPark ${ }^{\mathrm{TM}}$ ), or through questionnaires, e.g., Auchincloss et al. (2015); Bianco (2000). Moreover, several companies have invested heavily in their "smart parking" technologies (e.g., Deteq, Fybr, Streetline, Libelium, etc.). In our macroscopic model, however, we have the advantage that we do not require very specific parking data. Without any physical devices nor data collection efforts, we provide general results regarding the effects of parking pricing on a dynamic traffic network under realistic conditions.

For determining parking pricing, Arnott et al. (1991) were among the first to study parking in network equilibrium models. Because of the use of a parking fee policy to control the congestion of the city, low-income workers would try to avoid paying high parking fees and park further away from their destination in the city center. Their model, however, did not take into account traffic performance, i.e., the traffic performance parameters (e.g., travel speed) were assumed as fixed for all conditions in the model. Qian and Rajagopala (2013) modeled a system optimal parking flow minimization problem that follows a real-time pricing approach for a parking lot, based on its occupancy rate. They assumed a user equilibrium travel behavior and focused on the pricing of off-street parking facilities, but that may not be transferred directly to an on-street parking pricing model. Qian and Rajagopal (2014) presented a parking pricing model that minimizes the total travel time of the system according to real-time occupancy collected by parking sensors. This parking pricing problem under stochastic demand was later extended to investigate both departure time choices and parking location choices (Qian and Rajagopal (2015)). The resulting stochastic control problem managed the parking demand by adjusting the parking prices based on the occupancy rate. Our research, however, uses both, parking occupancy and searching traffic to maximize the revenue for a city while simultaneously minimizing the total searching time on the network. Mackowski et al. (2015) developed a dynamic Stackelberg leader-follower game theory approach to model variable parking prices in real-time for effective parking access and space utilization. In Lei and Ouyang (2017) a demand-driven dynamic location-dependent parking pricing and reservation strategy was used to improve the system-wide performance of an intelligent parking system. The drivers were allowed to make parking reservations prior to their trips and secure parking spaces for a future time period. These models provide a long-term demand management strategy capturing user competition and considering market equilibrium, while our model provides an aggregate parking pricing methodology focusing on the short-term effects on traffic performance. Ayala et al. (2012) worked on a pricing model that sets the parking fees such that the total driving distance is minimized in the system. A static parking demand is assumed, i.e., the model cannot replicate a dynamic real-world environment. In recent research, Van Nieuwkoop (2014) combined a traffic assignment model (Wardrop (1952)) and a parking search model into one single dynamic link-based methodology that is formulated as a mixed complementarity problem (MCP). By making a distinction between curbside and garage parking spaces and a differentiation of user classes with respect to their value of time (VOT), the model aimed to analyze the efficiency and distributional effects of different parking fee policies and to impose a demand-responsive pricing scheme for parking. This agent-based MCP model has interesting results regarding the impact of parking fee policies on cruising and congestion. Our proposed model has similar goals, but from a macroscopic perspective with much less data requirements and lower computational costs. Arnott and Rowse (2009) developed an on-street parking policy with identical agents for a medium-sized city. Their results showed that garage parking spaces are overpriced compared to on-street parking spots. Zhang et al. (2011) introduced a duration dependent parking fee regime based on daily travel cost in a linear city. Wang et al. (2015) investigated an optimal parking pricing problem in a park-and-ride $(\mathrm{P}+\mathrm{R})$ network with multiple origins and 
one destination. Their objective was to minimize the total travel cost by setting optimal parking fees at $\mathrm{P}+\mathrm{R}$ terminals. Other researches (Anderson and de Palma (2004)) analyzed the parking pricing economics more formally and showed that the social optimum can be achieved if the parking garages are owned privately. In comparison with these approaches, our proposed model requires very limited data, as we do not need individual vehicle or parking spaces information.

In Zheng and Geroliminis (2016) a congestion- and cruising-responsive feedback parking pricing scheme was illustrated based on a macroscopic approach for modeling a multi-modal traffic system with parking limitation and cruising-for-parking flow. The proposed framework was based on the Macroscopic Fundamental Diagram (MFD) reflecting the dynamics of parking flows in an urban network (Geroliminis $(2009,2015)$ ). The model uses feedback pricing controllers to realize a congestion- and cruising-responsive parking pricing scheme. The aggregated and dynamic pricing strategies were developed for large-scale network applications. Our research, in comparison, builds on a homogenous network environment that can be considered as a subnetwork or initial building block; with which further analysis can be developed later for more complex situations (e.g., where parking spaces or the parking prices are not homogenously distributed). For a case where there are different areas, each with a different distribution of parking spaces and parking prices, for example, one could use different subnetworks connected to each other.

In this research, we formulate a new parking pricing scheme and integrate it into the macroscopic traffic and parking model from Cao and Menendez (2015) in order to develop a parking pricing model and estimate its influence on the searching-for-parking traffic. The original methodology, validated already in Cao et al. (2017), uses a parking-statebased matrix to model the interactions between urban parking and traffic macroscopically over time. With such matrix, the model provides an approximation of the proportion of cars searching for parking, as well as an approximation of the time cars spent searching for parking, or traveling through the system. The original model, however, cannot account for pricing nor different values of time. Thus, in this paper we propose a parking pricing and decision model to fill this gap. Then, we compute all the variables associated with cruising for parking under the influence of our responsive parking pricing fee over time. The macroscopic responsive pricing scheme, taking the parking search phenomenon into consideration, is modeled as an optimization problem to maximize revenue while minimizing the cruising time on the network. In contrast with previous studies that only take the parking occupancy into account, here the parking fee changes in response to both, the parking occupancy, and the number of searching vehicles. The optimization model is formulated to maximize the parking pricing revenue to the highest level such that the cost of paying the current parking fee remains smaller than the cost of keep on searching to obtain a lower parking fee (i.e., so the total cruising time on the network is minimized). In general, in the parking pricing model, when a searcher finds an available parking space, he makes the decision to stay or to keep on searching based on several cost factors:

- the drivers' VOT;

- the current parking fee;

- the expected cost of keep on searching (which include the predicted future parking fee, the costs associated with traveling to the next parking possibility, and a penalty for past cruising time).

The average number of drivers that decide to park in a given time interval is computed then based on these costs, and the traffic and parking conditions can be found over time. Based on that, we analyze the efficiency of the proposed parking pricing scheme and its short-term influence on the urban traffic and parking systems. These short-term effects include:

- the searching-for-parking traffic (cruising);

- the congestion in the network (traffic performance);

- the total driven distance (environmental conditions); and

- the revenue created by parking fees for the city.

The maximal parking fee will evidently increase the revenue for the city in the short-term. It could also, in the longterm, deter drivers from driving into the city, potentially changing the demand. These long-term effects, however, are considered out-of-scope for this paper. Instead, we concentrate on modeling the short-term effects, including not only the financial benefits of the parking pricing scheme, but also the benefits (or disbenefits) that this might bring to the area's traffic system. The responsive parking pricing model is illustrated in a case study of an area within the city of Zurich, Switzerland. In addition, it is compared to other three alternative parking pricing scenarios, including a free, a constant, and an occupancy-responsive parking pricing scheme where the fee only changes in response to the parking occupancy. 
Most of the existing studies model travelers' parking preferences and decisions microscopically. Such studies tend to require huge amounts of data, and high levels of detail both on the demand and the supply side. In this research, we focus only on average values and probability distributions across the network, i.e., we look at the problem macroscopically. Thus, there is no data requirement for individual drivers or parking spots, as all data requirements correspond to aggregated values at the network level. Compared to microscopic approaches, this not only saves on data collection efforts (e.g., drivers' parking fee preferences, individual driving routes, individual parking spots turnovers) but also reduces the computational costs significantly. This is especially useful for real-time control algorithms or when the data is scarce.

The paper is organized as follows. Section 2 presents the overall methodology of the macroscopic parking pricing model. It is integrated into the matrix that describes the system dynamics of urban traffic based on its parking-related states and transition events. Section 3 introduces the analytical framework for the dynamic macroscopic responsive parking pricing. It includes a cost analysis for the cost of staying at the current parking space and the cost of keep on searching with the detailed description of all the relevant cost variables. Section 4 shows a case study of an area within the city of Zurich, Switzerland, to explore the use of the concept and the proposed methodology. Section 5 summarizes the findings of this paper.

\section{Framework}

In this section, the methodology of the dynamic macroscopic parking pricing and parking decision model is developed. It builds on the parking-state-based matrix proposed by Cao and Menendez (2015). An overview of the assumptions, inputs and outputs is shown below.

\subsection{Overview of the parking-state-based matrix}

The entire model is described in detail in Cao and Menendez (2015), but for the readers' convenience, the core parts including the macroscopic network setup are summarized again here.

- The study considers a small urban area as a relatively homogeneous network.

- The total time domain is split into small time slices (e.g., 1 minute), and the traffic/parking conditions are assumed steady within each time slice, although they can change over multiple time slices.

- All the assumed trips in this network are exclusively made by car (i.e., the mode choice has been previously made). The total demand includes two types of vehicles, those that might search for parking at some point, and through traffic.

- This analysis includes identical on- and off-street parking spaces. However, vehicles that use private parking spaces or have parking permit reservations do not typically search for parking. Thus, they are considered as part of the through traffic. All existing parking spaces (not only the available ones) are on average uniformly distributed on the network. This is reasonable for small areas with standard parking policies/provision (e.g., downtown areas or portions thereof).

- The traffic demand is homogenously distributed over the network, and the parking searchers are homogenously distributed within the overall driving traffic. This is reasonable for small compact areas where parking is also more or less homogeneously distributed.

These assumptions aim at replicating typical conditions in a small downtown area, where traffic and parking spaces are more or less homogenously distributed. Inputs to this model are the demand, the size of the network, the amount of parking supply, and the distribution of parking durations. There are some distributions that describe parking duration better than others, see Richardson (1974), Lautso (1981), Cao and Menendez (2013); although in theory any distribution can be used, e.g., negative binomial, poisson (Cao and Menendez (2015)). The parking-state-based matrix, as an output of this model, estimates the proportion of cars cruising-for-parking and the cruising time, as well as the traffic conditions and parking usage over time. The matrix describes how vehicles transition from one parking-related state to another over time (as shown in Fig. 1(a)). It also accounts for the system dynamics of urban traffic and its interactions with the parking system over time.

Two types of traffic demands are considered in this network and they are generated simultaneously in each time slice. The first group of vehicles searches for parking. This portion of the traffic demand experiences five transition 
events in the area of interest as seen in Fig. 1(a). During one single time slice a vehicle may experience at most one of the transition events. The notation for the three parking-related traffic states and the five transition events is shown in detail in Table 1. The second group of vehicles does not search for parking, i.e., the vehicles can be considered as through traffic and/or heading to a given private or reserved parking spot. This portion of vehicles in Fig. 1(b) only experiences the transition events "enter the area" and "leave the area" in Table 1, and the decision to leave the area depends on their driven distance in the network. Each traffic state and transition event in Table 1 is explicitly modelled in Cao and Menendez (2015).

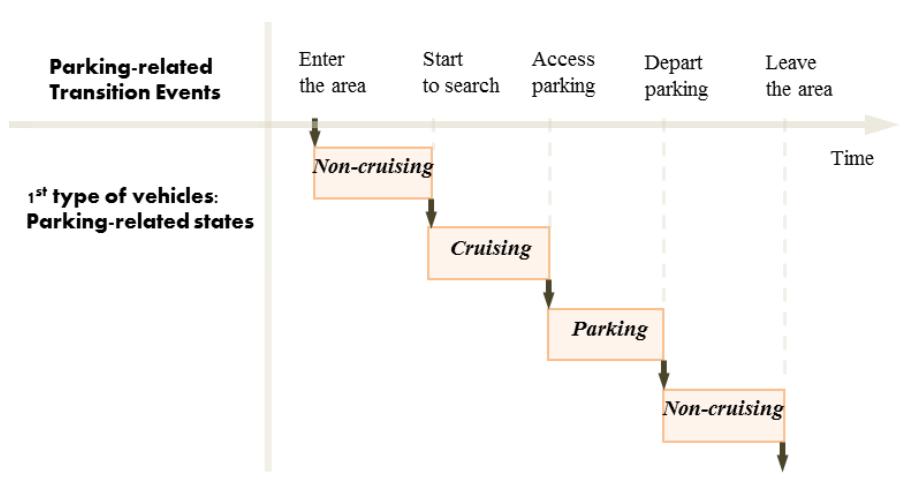

(a) First group of vehicles.

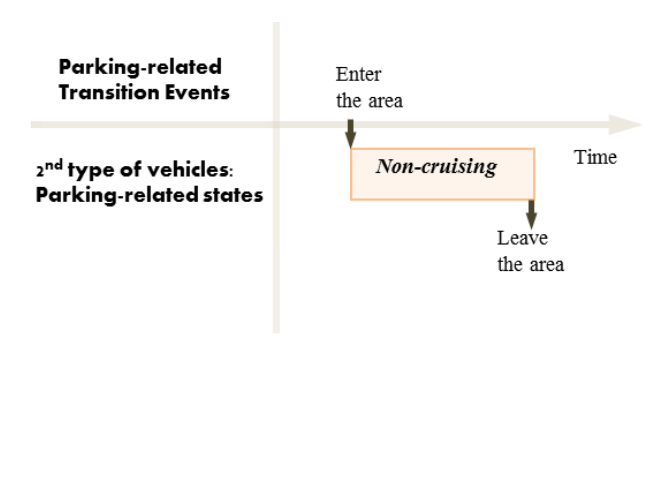

(b) Second group of vehicles.

Fig. 1. The transition events of urban traffic in-between different parking-related states (Source: Cao and Menendez (2015)).

All transition states are modelled using a deterministic approach. However, the model is not thoroughly deterministic, as for example, the parking location of each vehicle is not fixed, nor the travel time, nor the parking duration. The model is not thoroughly stochastic either as there are no random values involved in the computation of the transition events. Having a not thoroughly stochastic model does not necessarily make the model less valuable than one under completely stochastic conditions, because the model is meant to look for average values based on some probability distributions rather than the random values themselves (Cao and Menendez (2015)).

Table 1. Relevant key variables for matrix per time slice.

\begin{tabular}{lll}
\hline & Notation & Definition \\
\hline & $N_{n s}^{i}$ & Number of vehicles in the state "non-searching" at the beginning of time slice $i$ (Non-searching). \\
& $N_{s}^{i}$ & Number of vehicles in the state "searching" at the beginning of time slice $i$ (Searching). \\
& $N_{p}^{i}$ & Number of vehicles in the state "parking" at the beginning of time slice $i$ (Parking). \\
\hline$n_{/ n s}^{i}$ & Number of vehicles that enter the area and transition to "non-searching" during time slice $i$ (Enter the area). \\
& $n_{n s / \mathrm{s}}^{i}$ & Number of vehicles that transition from "non-searching" to "searching" during time slice $i$ (Start to search). \\
& $n_{s / p}^{i}$ & Number of vehicles that transition from "searching" to "parking" during time slice $i$ (Access parking). \\
& $n_{p / \mathrm{ns}}^{i}$ & Number of vehicles that transition from "parking" to "non-searching" during time slice $i$ (Depart parking). \\
$n_{n s /}^{i}$ & Number of vehicles that leave the area and transition from "non-searching" during time slice $i$ (Leave the area). \\
\hline
\end{tabular}

Based on some initial conditions, the output of the model is the parking-state related matrix. This matrix contains the number of vehicles experiencing each transition event as well as the resulting parking and traffic conditions (e.g., parking occupancy/availability and average travel speed) for each time slice. The conditions at any given time slice affect the transition events in the next time slice, so the matrix can be updated iteratively until the whole period is analyzed, or a defined criterion is reached (e.g., all the cars leave the area).

A case study for an area within the city of Zurich, Switzerland, was carried out in Cao et al. (2017) using this macroscopic model. Results showed that this model can be easily applied with limited data requirements and low computational costs, yielding relevant and trustworthy indicators of the cruising-for-parking phenomenon. This model 
is extended below to include a dynamic macroscopic parking pricing methodology.

\subsection{Basic information for analytical model}

Basic model assumptions, inputs, and expected outputs are briefly described below.

\section{Assumptions:}

Basic assumptions from Cao and Menendez (2015) for the matrix are kept here. They include, knowledge on the traffic demand over a period of time (e.g., a day), a homogeneous urban traffic network, knowledge on the distribution of parking durations, and knowledge on the length and traffic properties of the network. Following the same idea as the original model, here the urban network is abstracted as one ring road with cars driving in a single direction. Such ring road abstraction has been proven to be reasonable for small, homogeneous traffic networks (Daganzo (2011); Daganzo et al. (2011); Gayah and Daganzo (2011); Cao and Menendez (2015)). Since the traffic demand can be considered as homogenously distributed on the network, independently of vehicles travelling in a single direction or two, the assumption of a single travel direction simplifies the model without affecting the model results. Additionally, we assume no overtaking takes place. Although this seems unrealistic, it does not affect the model results: even if vehicles can overtake each other, for any given number of available parking spaces and searchers the average number of cars finding parking spaces in a time slice will not change.

The searching time and distance depend on the current traffic conditions, and on drivers' probability of finding an available parking spot (based on their own location, that of the available parking spots and the competitors). To specify each vehicle's driving time and driving distance, one normally needs to record the location of all cars and parking spots throughout the different time slices in the system. In this model, we can avoid that by using a macroscopic approach. We only consider the average number of vehicles that access parking during a time slice $i$, and the total/average searching distance driven during this time slice $i$. The number of available parking spots and the number of parking searchers are recorded over time in the parking-state-based matrix. However, their locations are not tracked. The following two assumptions are used in this model: First, we assume the stochastically independent distribution of parking availability on the network, i.e., at the beginning of each time slice $i$ the locations of available parking spots are assumed as random. Second: the traffic demand is homogeneously generated and the locations of all parking searchers are uniformly distributed on the network at the beginning of each time slice $i$. The second assumption is used to compute the average number of vehicles that find parking, and ultimately the average number of parking spots being taken. These average values only stand for a situation where, more or less all searchers are uniformly distributed on the network. This, however, limits the model. In reality, searchers can focus on one street to find parking while parking spots are easily available in other areas of the network. In this case, the model would likely overestimate the amount of parking spots being taken. However, the model does provide indicative and realistic results regarding the effects that parking might have on traffic performance under general conditions, as we are interested in whether there is on average at least one car that takes each available parking spot. For that, we do not need to know the exact location of each car or available parking spot.

In addition to these assumptions, we need to add some parking pricing specific assumptions to the macroscopic model. We assume that the VOT is different for individual vehicles depending on their user group. A user group can be dependent on the residents' location, income, careers, working states, etc. This VOT affects the parking decision of the cruising vehicles. All drivers are assumed to be risk-neutral, i.e., drivers are rational during their parking decision and only compare the relevant parking costs between deciding to park or keep on searching to find a better parking price. In reality, drivers with a low VOT might not keep on searching when the parking price increases and they might quit their journeys. Thus, we compute the best possible parking price such that only a small percentage of the population is affected by this "keep on searching" decision. In addition, we assume that drivers do not cancel their trips while searching for parking. The proportion of new arrivals that corresponds to traffic that is not searching for parking (i.e., through-traffic) is assumed to be independent of vehicles' VOT. The total traffic demand for all time slices, including the actual parking demand can be obtained based on simulations, demand models, city statistics, or other sources. The percentage of the demand that does not search for parking represents the proportion of traffic that is driving through this area but has a destination outside or is going to reserved parking spaces. The distance that must be driven by a vehicle before it starts to search for parking is also assumed to be independent of vehicles' VOT. As 
stated before, vehicles that use private parking spaces or have parking permit reservations do not typically search for parking. Thus, they are considered as part of the through traffic. As soon as the vehicles enter the parking-state, the parking fee needs to be paid at the rate of the arrival time, i.e., the unit parking pricing is assumed to be independent of the vehicle's parking duration.

\section{Inputs:}

Corresponding to the assumptions described above, Table 2 shows all the model's independent variables.

The first set corresponds to the travel demand. These variables can be estimated based on some historical data, e.g., traffic data on main roads to enter the network; parking data from one day's data collection, etc.

The second set corresponds to the parking system, traffic network, and model parameters. These variables can be estimated based on real measurements, the macroscopic fundamental diagram, and/or simulation results. The distance one needs to drive before transitioning into the next state can be reasonably assumed based on the length of the network, and other data collected from travelers.

The third set corresponds to the initial conditions of the parking-related states. These variables can be measured, assumed or simulated.

The fourth set corresponds to parking pricing specific input parameters. These variables can be estimated based on historical parking pricing data, or defined otherwise.

Table 2. Independent variables (inputs to the model).

\begin{tabular}{|c|c|c|}
\hline & Notation & Definition \\
\hline \multirow{4}{*}{ 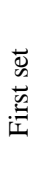 } & K & Total number of user groups for demand input of the network. Each user group has a different VOT. \\
\hline & $V O T^{k}$ & VOT for user group $k \in K$. \\
\hline & $n_{/ n s}^{i, k}$ & New arrivals to the network for user group $k \in K$ during time slice $i$ (i.e., travel demand per VOT user group) \\
\hline & $\beta^{i}$ & Proportion of new arrivals during time slice $i$ that corresponds to traffic that is not searching for parking. \\
\hline \multirow{7}{*}{$\begin{array}{l}\vec{d} \\
\infty \\
\vec{\Xi} \\
\tilde{D} \\
\tilde{n}\end{array}$} & $A$ & Total number of existing parking spaces (for public use) in the area. \\
\hline & $l_{n s / s}$ & Distance that must be driven by a vehicle before it starts to search for parking. \\
\hline & $l /$ & Distance that must be driven by a vehicle before it leaves the area without parking. \\
\hline & $L$ & Size (length) of the network. \\
\hline & $v$ & Free flow speed, i.e., maximum speed in the network, including stopped time at intersections. \\
\hline & $T$ & Length of the simulation's time horizon. \\
\hline & $t$ & Length of a time slice. \\
\hline \multirow{3}{*}{ 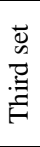 } & $N_{n s}^{0}$ & Initial condition for the non-searching state. \\
\hline & $N_{s}^{0, k}$ & Initial condition for the searching state for user group $k \in K$. \\
\hline & $N_{p}^{0}$ & Initial condition for the parking state. \\
\hline \multirow{4}{*}{ 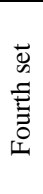 } & $p^{0}$ & Initial parking pricing for all available parking spaces. \\
\hline & $\Delta_{\max }$ & Maximum increase/decrease in pricing per time slice. \\
\hline & $\eta_{\text {pred }}$ & Fixed number of time interval slices to include for approximation of predicted parking pricing. \\
\hline & $p_{\text {dist }}$ & Price per kilometer driven on the network (i.e., external costs as petrol, wear and tear of vehicles). \\
\hline
\end{tabular}

\section{Outputs:}

The model provides, amongst others, the results of the interactions between the dynamic responsive parking pricing system, the urban parking system, and the urban traffic system. The responsive pricing output over time and its interdependency with cruising vehicles can be studied. The short-term effects of parking pricing on traffic conditions can be investigated, i.e., the distance driven and the time spent by both, vehicles searching and vehicles not searching. Besides these environmental, cruising-for-parking, and traffic performance effects, we also analyze the revenue created by parking fees for the city.

Table 3 shows a list of new variables we define and use in our methodology. The first set is used to quantify the 
number of vehicles that experience each transition event in a time slice. The second set corresponds to the parking pricing model and the cost variables that are used to compute the vehicles deciding to park. The third set is used to compute these cost variables.

Table 3. Intermediate model variables.

\begin{tabular}{|c|c|c|}
\hline & Notation & Definition \\
\hline \multirow{5}{*}{ 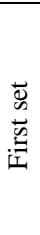 } & $n_{n s / s}^{i, k}$ & Number of vehicles that transition from "non-searching" to "searching" for user group $k \in K$ during time slice $i$. \\
\hline & $N_{s}^{i, k}$ & Number of vehicles in the searching state for user group $k \in K$ during time slice $i$. \\
\hline & $A^{i}$ & Number of available parking spaces at the beginning of time slice $i$. \\
\hline & $v^{i}$ & Average travel speed in time slice $i$, including stopped time at intersections. \\
\hline & $d^{i}$ & Maximum driven distance per vehicle in time slice $i$. \\
\hline \multirow{6}{*}{$\begin{array}{l}\overrightarrow{0} \\
\infty \\
\overrightarrow{0} \\
0 \\
\tilde{D} \\
\tilde{n}\end{array}$} & $p^{i}$ & Responsive parking fee for all available parking spaces during time slice $i$. \\
\hline & $C_{t o t}^{i, k}$ & Total costs of keep on searching to a next available parking possibility for each user group $k \in K$ at time slice $i$. \\
\hline & $C_{\text {pay }}^{i}$ & $\begin{array}{l}\text { Costs for the predicted parking fee at all available parking spaces for the next future time slices, predicted at the beginning } \\
\text { of time slice } i \text {. }\end{array}$ \\
\hline & $\Delta C_{\text {pay }}^{i}$ & Change of costs for the predicted parking fee at the beginning of time slice $i$. \\
\hline & $C_{\text {dist }}^{i, k}$ & $\begin{array}{l}\text { Costs of driving from a given available parking space to the next parking possibility (i.e., external costs as petrol, wear and } \\
\text { tear of vehicles) for each user group } k \in K \text { at time slice } i \text {. }\end{array}$ \\
\hline & $C_{\text {pen }}^{i, k}$ & $\begin{array}{l}\text { Costs for penalty term with respect to past cruising time (i.e., driving costs in past iterations) for each user group } k \in K \text { at } \\
\text { time slice } i \text {. }\end{array}$ \\
\hline \multirow{4}{*}{ 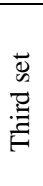 } & $r^{i}$ & Expected average road travel distance from a given available parking space to the next parking possibility. \\
\hline & $\delta_{\text {park }}^{i, k}$ & A binary indicator of vehicles' decision to park (or not) for each user group $k \in K$ in time slice $i$. Its value is either 1 or 0 . \\
\hline & $A C T^{i}$ & Average cruising time per vehicle at the beginning of time slice $i$. \\
\hline & $C T_{\max }^{i}$ & Maximum cruising time per vehicle at the beginning of time slice $i$. \\
\hline
\end{tabular}

\subsection{Transition events}

Below we introduce the modification of the transition events "Enter the area", "Start to search", "Access parking", "Depart parking", and "Leave the area" as presented in Table 1 from Cao and Menendez (2015). The transition events are now adapted to include vehicles from different VOT user groups in the network, and the decision to park or not with respect to parking pricing.

\subsubsection{Enter the area}

The number of vehicles entering the area and transitioning to "non-searching-state" (transition event "Enter the area") during time slice $i, n_{/ n s}^{i}$, is an input to the model. For any given time slice $i, n_{/ n s}^{i}=\sum_{k=1}^{K} n_{/ n s}^{i, k}$, where $n_{/ n s}^{i, k}$ is the number of vehicles from user group $k$, and $K$ is the total number of user groups. Each user group has a different VOT, $V O T^{k}$.

Among these vehicles, a number of $\beta^{i} \cdot n_{/ n s}^{i}$ vehicles do not search for parking and will directly leave the area after driving a distance $l /$. The remaining percentage, $1-\beta^{i}$, will go through all transition events. $\beta^{i}$ is assumed to be $k$-independent for $k \in K$.

\subsubsection{Start to search}

We assume that the vehicles start to search after driving a distance $l_{n s / s}$ since they enter the area. $l_{n s / s}$ can be assumed as a fixed value or to follow any given probability density function. In Cao (2016), an in-depth sensitivity analysis was conducted to quantitatively evaluate the effects of this variable on the model output. The outcomes show 
that the model results are not sensitive to the value of $l_{n s / s}$. For simplicity, here we assume $l_{n s / s}$ is not dependent on the individual user group $k \in K$. Eq. (1) shows the number of vehicles $n_{n s / s}^{i, k}$ starting to search for parking during time slice $i$.

with

$$
n_{n s / s}^{i, k}=\sum_{i^{\prime}=1}^{i-1} \underbrace{\left(1-\beta^{i^{\prime}}\right) \cdot n_{/ n s}^{i^{\prime}, k}}_{\text {term } 1} \cdot \underbrace{\gamma_{n s / s}^{i^{\prime}}}_{\text {term } 2}
$$

$$
\gamma_{n s / s}^{i^{\prime}}= \begin{cases}1, & \text { if } l_{n s / s} \leq \sum_{j=i^{\prime}}^{j=i-1} d^{j} \text { and } \sum_{j=i^{\prime}}^{j=i-1} d^{j} \leq l_{n s / s}+d^{i-1} \\ 0, & \text { if otherwise }\end{cases}
$$

The number of vehicles $n_{n s / s}^{i, k}$ in Eq. (1) consists of vehicles from user group $k \in K$ that have entered the network area in any slice between 1 and $i-1$. Here we use $i^{\prime} \in[1, i-1]$ to denote such a time slice. Term 1 in Eq. (1) shows all the vehicles that have entered the area before time slice $i$ and need to park. Term 2 is a binary variable indicating whether these vehicles will start to search for parking in time slice $i$ or not. The vehicles start to search in case they have driven the required distance $l_{n s / s} \leq \sum_{j=i^{\prime}}^{j=i-1} d^{j}$, and in case they have not started to search in a former time slice (condition: $\sum_{j=i^{\prime}}^{j=i-1} d^{j} \leq l_{n s / s}+d^{i-1}$ ). Notice that $d^{i}=v^{i} \cdot t$ is defined as the maximum driven distance of the vehicles in time slice $i$ based on the average travel speed $v^{i}$ in that time slice. Evidently, in reality, not all cars will drive the full distance before transitioning to another event on a given time slice. However, it is trivial to show that the bias of $d^{i}$ becomes negligible as the length of the time interval $t$ becomes very small (in this case, $1 \mathrm{~min}$ ).

\subsubsection{Find and access parking: Parking pricing and parking decision}

One of the goals of this paper is to propose a dynamic macroscopic parking pricing model with its interdependency with searching-for-parking traffic. It is included into a traffic system with a parking search model over time to replicate reality.

In the transition event "Find and access parking" when drivers find an available parking space, they make the decision to park or to keep on searching for the next parking possibility.

- Vehicles finding parking: We compute the portion of vehicles finding parking as those in the transition event $n_{s / p}^{i}$ (“Access parking") in Cao and Menendez (2015). The formulation is based on probability theory, and it depends on the number of available parking spaces $A^{i}$, the number of vehicles searching for parking $N_{s}^{i}$, and the maximum driven distance per vehicle in a given time slice $d^{i}$.

- Vehicles deciding to park: The number of vehicles that do access parking (i.e., transition from "searching" to "parking"-state) is adapted depending on the vehicles deciding to park based on the parking price as illustrated in Fig. 2. 


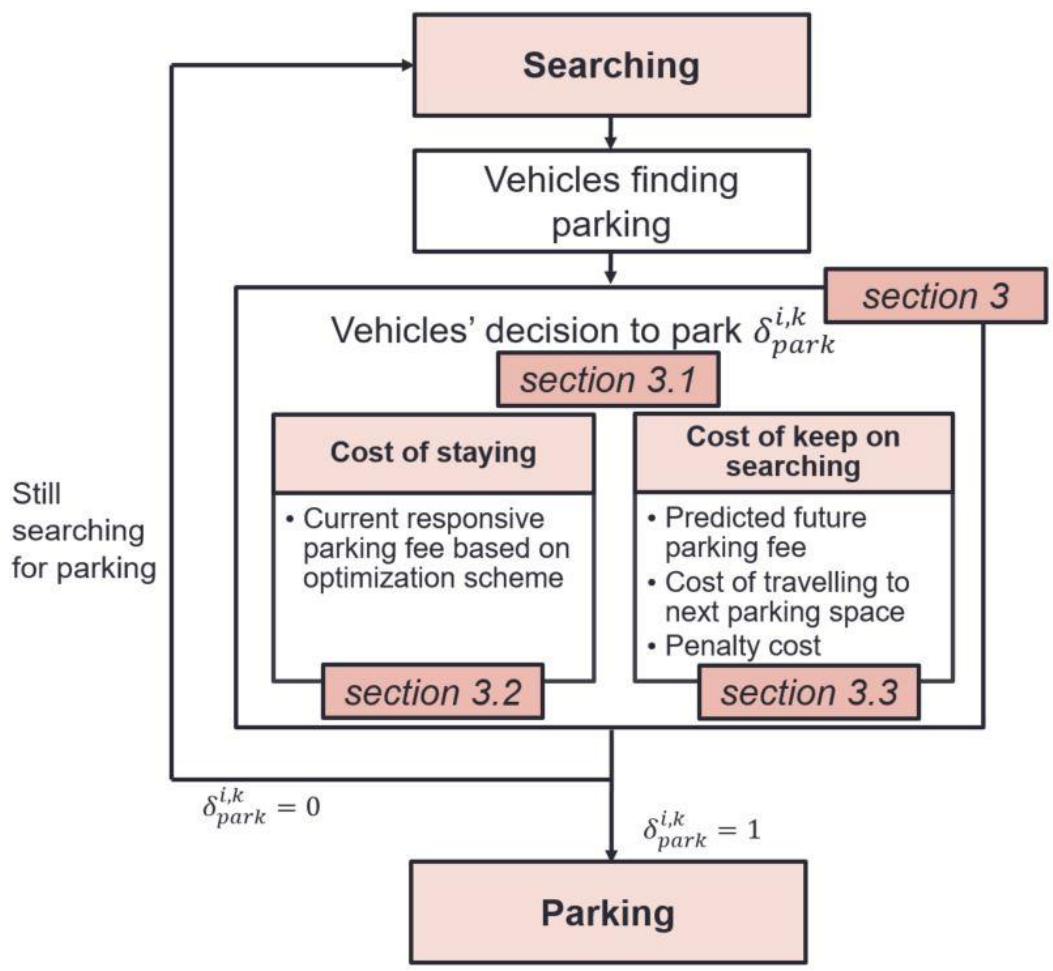

Fig. 2. Modelling of parking pricing and its effect on the transition between the "searching" and "parking"-state.

Fig. 2 shows an overview of our dynamic responsive parking pricing model within the structure of this paper, that includes the vehicles finding parking (Cao and Menendez (2015)) and the vehicles deciding to park (section 3). This last section explains the main model to determine the vehicles deciding to park (section 3.1), depending on the cost of staying (section 3.2), and the cost of keep on searching (section 3.3). All costs are determined macroscopically without stochastic components, using average values and probability distributions across the whole population. In section 3.1, the vehicles' decision to park $\delta_{\text {park }}^{i, k}$ is determined for each user group $k \in K$. This models the decision process to park or to keep on searching dynamically. Incorporating the cost of staying and the cost of keep on searching, $\delta_{\text {park }}^{i, k}$ refers to the vehicles' decision to park at the current parking space for each user group $k$.

The decision to stay (i.e., park) or keep on searching is modelled mathematically and depends on various influence factors. Below we provide an overview of those influence factors. More details are given in section 3.

- Cost of staying: The cost of staying in section 3.2 represents the current parking price. The dynamic responsive parking fee over time is computed macroscopically as the outcome of an optimization model. By maximizing the revenue for a city while simultaneously minimizing the cruising time for every time slice the parking fee is determined depending on the number of vehicles $N_{s}^{i}$ in the searching-state and the number of available parking spaces $A^{i}$.

- Cost of keep on searching: The cost of keep on searching in section 3.3 is computed based on the predicted parking fee in a future time slice (section 3.3.1), the costs associated with traveling to the next parking possibility (section 3.3.2), and some penalty for the past cruising time (section 3.3.3) in order to avoid an ever searching vehicle.

For the next time slice $i+1$, the number of vehicles $N_{s}^{i+1}$ in the searching-state is computed according to Eq. (2a) and (2b), they are a modification of the searching-state formulation in Cao and Menendez (2015). First, $N_{s}^{i+1, k}$ is determined in Eq. (2a) for each user group $k \in K$. Then, we compute $N_{s}^{i+1}$ in Eq. (2b) as the sum over all user groups $k$. 


$$
\begin{gathered}
N_{s}^{i+1, k}=N_{s}^{i, k}+n_{n s / s}^{i, k}-\underbrace{n_{s / p}^{i} \cdot \frac{N_{s}^{i, k}}{N_{s}^{i}}}_{\text {term } 1} \cdot \underbrace{\delta_{\text {park }}^{i, k}}_{\text {term } 2} \\
N_{s}^{i+1}=\sum_{k=1}^{K} N_{s}^{i+1, k}
\end{gathered}
$$

For any given time slice, term 1 in Eq. (2a) represents the number of vehicles that have found parking. The vehicles will then decide whether to access parking or not, depending on the parking decision variable $\delta_{\text {park }}^{i, k}$ in term 2 for user group $k$. The vehicles will access parking when $\delta_{\text {park }}^{i, k}=1$, and they will keep on searching for a next parking possibility when $\delta_{\text {park }}^{i, k}=0$. Note that we assume that the ratio of the vehicles in the searching-state from user group $k$ is the same as the ratio of the vehicles finding parking from user group $k$. Thus, the portion of vehicles having found parking that belong to user group $k$ is represented by the ratio $\frac{N_{s}^{i, k}}{N_{s}^{i}}$ in term 1 .

\subsubsection{Depart parking and leave the area}

The number of vehicles that depart parking and the number of vehicles that leave the area are computed as in Cao and Menendez (2015). The former is a function of the distribution of parking durations. The latter is a function of some minimum driven distance.

\section{Macroscopic parking pricing and parking decision model}

In this section, the modelling parts and the analytical formulations for the dynamic macroscopic responsive parking pricing and parking decision methodology are shown. Here we propose the dynamic algorithms for the vehicles deciding to park (or not), including a cost analysis for the corresponding cost of staying and the cost of keep on searching for the next parking possibility, with the detailed description of all relevant cost variables.

\subsection{Main model}

Recall that $p^{i}$ is the actual parking fee for all available parking spaces at time slice $i$, i.e., all parking spaces are assumed to have the same parking fee at any given time slice but the value changes over time. Thus, this leads to uniform price changes over the network. Notice that for a case where there are different areas each with a different distribution of parking spaces and parking prices, for example, one can use different subnetworks connected to each other, each modeled as the network presented here.

For all parking searchers to decide to park, we check the following condition

$$
p^{i} \leq C_{t o t}^{i, k}
$$

i.e., we check whether the parking price at the current parking space $p^{i}$ is smaller than the cost of keep on searching to the next possible parking space (i.e., $C_{\text {tot }}^{i, k}$ for each user group $k \in K$ ). Since we do not track individual parking spaces, the average travel distance between available parking spaces is used as an indicator for the next possible parking space on the network. If Eq. (3) is fulfilled, the drivers decide to park at their current parking locations in time slice $i$. Otherwise the drivers will keep on searching hoping to find a better parking price, and as soon as they arrive at their next parking possibility, Eq. (3) will be checked again. Recall that we assume that all drivers are risk neutral and completely rational.

Now the vehicles' decision to park (or not) is indicated as $\delta_{\text {park }}^{i, k}$ in Eq. (4). Its value equals 1 if Eq. (3) is fulfilled for user group $k$; otherwise the value equals 0 , illustrating the decision to keep on searching for the next parking possibility. The decision is the same for all drivers belonging to the same user group, but it might be different across 
different user groups.

$$
\delta_{\text {park }}^{i, k}=\operatorname{Prob}\left(p^{i} \leq C_{\text {tot }}^{i, k}\right)= \begin{cases}1, & \text { if } p^{i} \leq C_{\text {tot }}^{i, k} \\ 0, & \text { otherwise }\end{cases}
$$

To obtain $\delta_{\text {park }}^{i, k}$ in Eq. (4), $p^{i}$ and $C_{\text {tot }}^{i, k}$ will be further modelled. Note that $\delta_{\text {park }}^{i, k}$ has the same value for all parking spaces in a small compact area.

We now show the computation of $p^{i}$ by using an optimization model in section 3.2 and then estimate $C_{\text {tot }}^{i, k}$ in section 3.3 .

\subsection{Cost of staying}

The cost of staying, i.e., the parking fee over time is now presented as the outcome of an optimization model. This parking price changes in response to both, the parking occupancy, $A^{i}$, and the number of searching vehicles, $N_{s}^{i}$. In reality, $N_{s}^{i}$ might be obtained with the help of connected vehicles and we assume this information will become available in the future. For cases where exact information regarding the number of searchers is not available, simple estimations based on the overall demand pattern could be used. For this algorithm $A^{i}$ and $N_{s}^{i}$ at the beginning of each time slice are found based on the parking-state-based matrix over time. The ratio between the number of searchers $N_{s}^{i}$ and the number of available parking spots $A^{i}$ changes from one time slice to the next. This change is formulated as written in Eq. (5).

$$
\Delta \frac{N_{s}^{i}}{A^{i}}=\frac{N_{s}^{i}}{A^{i}}-\frac{N_{s}^{i-1}}{A^{i-1}}
$$

By maximizing the revenue for a city while simultaneously minimizing the cruising time for each time slice, the parking fee $p^{i}$ is determined as a multi-objective optimization problem in Eq. (6a-c). The resulting parking price, $p^{i}$, is then known at the beginning of each time slice $i$.

$$
\begin{array}{r}
\max _{p^{i}}(\underbrace{p^{i} \cdot \frac{n_{s / p}^{i}}{N_{s}^{i}} \cdot \sum_{k=1}^{K} N_{s}^{i, k} \cdot \delta_{\text {park }}^{i, k}}_{\text {term } 1} \underbrace{\sum_{k=1}^{K}\left(C_{\text {tot }}^{i, k}-p^{i}\right)}_{\text {term } 2}) \\
\text { s.t. }\left|p^{i}-p^{i-1}\right| \leq \begin{cases}0, & \text { if } \Delta \frac{N_{s}^{i}}{A^{i}}=0 \\
\Delta_{\text {max }}, & \text { otherwise }\end{cases} \\
p^{i} \geq p^{0}
\end{array}
$$

The revenue maximization is stated as the objective function term 1 in Eq. (6a) where all vehicles from all user groups $k \in K$ having decided to park (as seen in Eq. (2a)) pay the parking fee $p^{i}$. The cruising time minimization is expressed by having Eq. (3) for each user group $k$ as a soft constraint in the objective function term 2 in Eq. (6a) where $C_{\text {tot }}^{i, k}$ is dependent on the number of vehicles $N_{s}^{i}$ in the searching-state and the number of available parking spaces $A^{i}$. This means that in case Eq. (3) is violated for user group $k$, i.e., $p^{i}>C_{\text {tot }}^{i, k}$, the optimization problem will be solved, although it will lead to additional cruising $\left(\delta_{\text {park }}^{i, k}=0\right)$ for user group $k$ in time slice $i$. However, this optimization problem tries to satisfy Eq. (3) and to guarantee the same traffic performance on the network compared to a free parking scenario without parking pricing, i.e., it tries to implement a parking pricing scheme with a maximal revenue, while keeping the same travel time and distance as in a case without parking pricing (see more details in section 4.2). Evidently, we cannot do better than the scenario without parking pricing, but we can reach the same (or similar) traffic performance results, while collecting revenue for the city. We would like to find the maximal parking 
price $p^{i}$ for any given time slice such that $\delta_{\text {park }}^{i, k}=1$ for each user group $k$. In other words, what is the maximal price we could choose such that the drivers still decide to park and not keep on cruising for a better parking price in the future. At the end of the simulation $(i=T)$ this concept will lead to a maximal revenue for a city while simultaneously minimizing the total cruising time on the network. As shown in Eq. (6b), the absolute price difference between $p^{i}$ and $p^{i-1}$ should not exceed the maximum pricing change input parameter $\Delta_{\max }$ to reduce the oscillations of the optimal parking pricing output (i.e., avoid drastic price fluctuations). Additionally, if the ratio between $N_{s}^{i}$ and $A^{i}$ in Eq. (5) is equal to zero, then we determine the parking fee as $p^{i}=p^{i-1}$, a constant price compared to the parking price $p^{i-1}$ in the last time slice $i-1$. Last but not least, as shown in Eq. (6c), the parking fees should not go below the initial parking prices.

This convex optimization problem can be solved with a simple numerical solver. It is also possible to include scale parameters within $C_{t o t}^{i, k}$ to weight each decision cost from section 3.3 in the optimization model. $C_{\text {tot }}^{i, k}$.

In the next section, we present the formulations for the cost of keep on searching for another parking possibility

\subsection{Cost of keep on searching}

The total cost of keep on searching $C_{\text {tot }}^{i, k}$ is computed for each user group $k \in K$ based on multiple cost terms as shown in Eq. (7) which are derived in the following subsections.

$$
C_{\text {tot }}^{i, k}=C_{\text {pay }}^{i}+C_{\text {dist }}^{i, k}+C_{\text {pen }}^{i, k}
$$

This includes:

- the $\operatorname{cost} C_{\text {pay }}^{i}$ for the predicted parking fee at all available parking spaces for the next future time slices, predicted at the beginning of time slice $i$ (subsection 3.3.1),

- the predicted cost $C_{\text {dist }}^{i, k}$ of traveling from a given available parking space to the next parking possibility (subsection 3.3.2),

- the penalty $\operatorname{cost} C_{\text {pen }}^{i, k}$, i.e., the driving cost associated with past iterations (subsection 3.3.3).

Note that only $C_{d i s t}^{i, k}$ and $C_{\text {pen }}^{i, k}$ are affected by the user group $k$ since these are the only cost variables including a time component that is associated with the drivers' VOT.

\subsubsection{Predicted future parking fee, $C_{\text {pay }}^{i}$}

The term $C_{\text {pay }}^{i}$ is the parking fee at all available parking spaces for the next future time slices, predicted at the beginning of time slice $i$. We assume the parking fee in the next future time slice $i+1$ dictates the parking pricing we would pay in all next future time slices. We assume the driver predicts this future price with some information he/she has about the system (based on his/her own observations). Given that the parking price in this model is dependent on the number of searching vehicles $N_{s}^{i}$ and the number of available parking spaces $A^{i}$ from past iterations we use both variables to predict future pricing, i.e., we assume the driver has some very recent historical information available about the traffic and parking systems. Thus, in this predicted parking pricing scheme the future parking price $C_{\text {pay }}^{i}$ changes in response to $N_{s}^{i}$ and $A^{i}$ from past iterations, i.e., this pricing scheme not only focuses on the parking occupancy, but also takes the parking search phenomenon into account.

The predicted change of the parking fee $\Delta C_{\text {pay }}^{i}$ is formulated in Eq. (8) as the pricing difference between the current and consecutive future time slices. The predicted forecasting strategy uses historical information about the ratios in Eq. (5) and the current parking price $p^{i}$. 


$$
\Delta C_{\text {pay }}^{i}=\underbrace{p^{i}}_{\text {term } 1} \cdot \underbrace{\left(\left|\Delta \frac{N_{s}^{i+1}}{A^{i+1}}\right|\right)^{\frac{1}{y}}}_{\text {term } 2} \approx p^{i} \cdot \underbrace{\left(\left|\Delta \frac{N_{s}^{i}}{A^{i}}\right|\right)^{\frac{1}{y}}}_{\text {term } 3} \cdot \underbrace{|\frac{1}{\eta_{\text {pred }}} \cdot \underbrace{}_{j=i-\eta_{\text {pred }}+1} \frac{\sum_{\Delta} \frac{N_{s}^{j-1}}{A^{j-1}} \mid}{A_{s}^{j}}|}_{\text {term } 4}
$$

where $\Delta \frac{N_{S}^{j-1}}{A^{j-1}} \neq 0$. In Eq. (8), term 1 is the current parking price $p^{i}$ and term 2 represents the future responsive quality to $\Delta C_{\text {pay }}^{i}$. Within term 2, $y$ characterizes the level of responsiveness, i.e., it changes the level of influence of $\Delta \frac{N_{s}^{i+1}}{A^{i+1}}$ on the delta pricing value $\Delta C_{\text {pay }}^{i}$. It can be shown in a sensitivity analysis that changes to the parameter $y>1$ only have a marginal influence on the total revenue results. This scale parameter, however, needs to be calibrated in future research such that it leads to reasonable pricing results over time that are acceptable for the drivers in the area. In the remainder of this paper, we assume a square root dependency and set $y=2$. An approximation for term 2 is computed by using term 3 and term 4 . This approximation has been validated by a data analysis from the case study in section 4, but the details are omitted in this paper for brevity. Term 3 in Eq. (8) refers to the current responsive impact term. Term 4 is estimated by the total average of increases/decreases over the last fixed $\eta_{\text {pred }}$ time slices, where $1 \leq$ $\eta_{\text {pred }} \leq i-1$ is an input parameter to the model. Thus, we consider all ratios $\Delta \frac{N_{s}^{j}}{A^{j}} \neq 0$ for $j \in\left\{i-\eta_{\text {pred }}, \ldots, i\right\}$ to get the aggregated predictive estimate in term 4 . For the input parameters $\eta_{\text {pred }}=1$, the approximation term 4 in Eq. (8) only considers the increase/decrease of the ratio $\Delta \frac{N_{S}^{j}}{A^{j}}$ from the time slice $i-1$ to the current slice $i$, while for $\eta_{\text {pred }}=i-1$ this estimate covers the total average of increases/decreases of the ratio $\Delta \frac{N_{s}^{j}}{A^{j}}$ for all previous time slices $j \in\{2, \ldots, i\}$. By properly setting this input parameter $\eta_{\text {pred }}$ in Eq. (8), we can make sure that the ratios $\Delta \frac{N_{s}^{j}}{A^{j}}$ for initial time slices $j$ have no impact on the predictive pricing for long simulations runs.

By using Eq. (8) we compute in Eq. (9) the actual predictive parking pricing fee $C_{\text {pay }}^{i}$ for all available parking spaces in the next future time slices. Notice that this value is just a prediction and will not necessary match the actual price set in future time slices.

$$
C_{\text {pay }}^{i}= \begin{cases}p^{i}+\min \left\{\Delta C_{\text {pay }}^{i}, \Delta_{\max }\right\}, & \text { if } \Delta \frac{N_{s}^{i+1}}{A^{i+1}}>0 \\ p^{i}, & \text { if } \Delta \frac{N_{s}^{i+1}}{A^{i+1}}=0 \\ p^{i}-\min \left\{\Delta C_{\text {pay }}^{i}, \Delta_{\max }\right\}, & \text { if } \Delta \frac{N_{s}^{i+1}}{A^{i+1}}<0\end{cases}
$$

For $\Delta \frac{N_{s}^{i+1}}{A^{i+1}} \gtrless 0$, we only consider $\Delta C_{\text {pay }}^{i}$ to increase or decrease $p^{i}$, if it is smaller than the maximum pricing change input parameter $\Delta_{\max }$. Otherwise this predicted pricing change is determined with $\Delta_{\max }$. For $\Delta \frac{N_{s}^{i+1}}{A^{i+1}}=0$, no pricing change is made.

\subsubsection{Predicted cost of traveling to next available parking space, $C_{\text {dist }}^{i, k}$}

$C_{\text {dist }}^{i, k}$ represents the predicted cost of traveling from a given available parking space to the next parking possibility. This cost is associated with the driving distance and with the drivers' VOT depending on their user group $k \in K$.

Recall that $L$ is the length of the network and $v^{i}$ the average travel speed in time slice $i$. We do not know the exact location of the available parking spaces, as they are assumed to be randomly distributed on the network. However, we define the road travel distance $r^{i}$ in Eq. (10) as an expected average value. 


$$
r^{i}=\frac{L}{A^{i}}
$$

With the aid of $r^{i}$ we get the expected average travel time $\frac{r^{i}}{v^{i}}$ between available parking spaces that depends mostly on two factors: (1) the number of available parking spaces $A^{i}$, and (2) the average speed $v^{i}$ in the traffic network. Both variables are updated in every time slice; $v^{i}$ is a function of the traffic density. This traffic density is in turn a function of the through-traffic proportion $\beta^{i}$, the searching traffic and its ability to find parking (for details see Cao and Menendez (2015)). We introduce the input variable $p_{\text {dist }}$, the price per unit distance. Then, $r^{i}$ and $\frac{r^{i}}{v^{i}}$ are both used to model $C_{\text {dist }}^{i, k}$ in Eq. (11),

$$
C_{d i s t}^{i, k}=\underbrace{r^{i} \cdot p_{\text {dist }}}_{\text {term } 1}+\underbrace{\frac{r^{i}}{v^{i}} \cdot V O T^{k}}_{\text {term } 2}
$$

where term 1 is associated with the actual driving distance (i.e., external costs as petrol, wear and tear of vehicles) and term 2 refers to the cost of time with respect to drivers' VOT. Recall VOT ${ }^{k}$ is the input parameter showing the VOT costs for each user group $k$.

\subsubsection{Penalty cost, $C_{\text {pen }}^{i, k}$}

Now we consider as well the driving cost $C_{\text {pen }}^{i, k}$ in past iterations to account for the time drivers have already searched. We model this in Eq. (12) by using the average cruising time per vehicle at the network level. The longer the average cruising time on the network is, the higher will be the penalty cost $C_{\text {pen }}^{i, k}$, and thus the total costs of keep on searching $C_{\text {tot }}^{i, k}$. This leads to a higher likelihood of drivers accepting the available parking spaces. This penalty cost term is defined as

$$
C_{p e n}^{i, k}=A C T^{i} \cdot V O T^{k}
$$

where $A C T^{i}$ is the average cruising time per vehicle at the beginning of time slice $i$, i.e., the average time a vehicle spends in the searching-state. For simplification purposes we assume that at any given time slice $i$, the average cruising time is the same for all user groups $k \in K$.

We now determine $A C T^{i}$ by computing the maximum cruising time $C T_{\max }^{i}$ per vehicle at the beginning of time slice $i . C T_{\text {max }}^{i}$ is estimated based on the queueing diagram in Fig. 3 showing the cumulative number of vehicles going through each transition event as a function of time. This diagram not only provides the basis for $C T_{\text {max }}^{i}$, it can also be used to estimate other interesting indicators for both the traffic and the parking systems, including the number of vehicles searching over time, and the total cruising time in the area at any given time slice. 


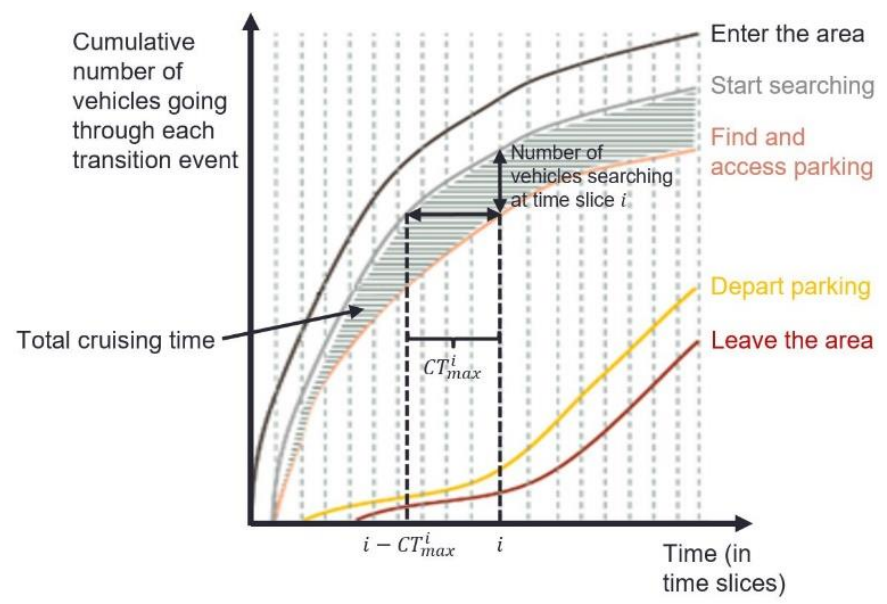

Fig. 3. Illustration of the maximum cruising time $C T_{\text {max }}^{i}$ at the beginning of time slice $i$ within the queuing diagram.

The maximum cruising time $C T_{\max }^{i}$ per vehicle can now be determined by using Eq. (13). As illustrated in Fig. 3 , this equation sets the cumulative number of vehicles that have started searching before the beginning of time slice $i$ equal to the cumulative number of vehicles that have found and accessed parking by the beginning of time slice $i$. Note that term 1 in Eq. (13) represents all vehicles for all user groups $k \in K$ having decided to park (as seen in Eq. $(2 a))$.

$$
\text { Find } C T_{\text {max }}^{i} \text {, s.t. } \sum_{j=1}^{i-C T_{\max }^{i}} n_{n s / s}^{j}=\sum_{j=1}^{i}(\underbrace{\frac{n_{s / p}^{j}}{N_{s}^{j}} \cdot \sum_{k=1}^{K} N_{s}^{j, k} \cdot \delta_{\text {park }}^{j, k}}_{\text {term } 1})
$$

Because all parking searchers are uniformly distributed on the network at the beginning of each time slice $i$, the average cruising time $A C T^{i}$ is now computed in Eq. (14) as half of $C T_{\max }^{i}$. Note that $A C T^{i}$ only includes the cruising time of vehicles that are still cruising for parking and it does not include the cruised time for vehicles that already found parking.

$$
A C T^{i}=\frac{C T_{\max }^{i}}{2}
$$

Eq. (13) and (14) show an approximation for the average cruising time per vehicle $A C T^{i}$ to determine $C_{\text {pen }}^{i, k}$ in Eq. (12).

\section{Applications}

In this section, a case study of an area within the city of Zurich, Switzerland, is provided to illustrate the interactions between a dynamic responsive parking pricing system and the traffic system. We use real data obtained by Cao et al. (2017) and present the results obtained from multiple simulation runs that are conducted with the aid of a simple numerical solver such as Matlab. We discuss the findings regarding parking pricing and the corresponding revenue in different pricing scenarios with its impact on the average/total searching time/distance in the network. 


\subsection{Case study of an area within the city of Zurich, Switzerland}

Fig. 4(a) shows the study area $\left(0.28 \mathrm{~km}^{2}\right)$ that is located around the department store Jelmoli in the city center of Zurich (Cao et al. (2017)). This very centric area within the city contains a significant amount of retail and office space mostly from the financial sector. The area has a radius of $0.3 \mathrm{~km}$ and contains a total of $L=7.7 \mathrm{~km}$ of road. Most streets have two lanes (either one per direction or two one-way lanes). There are a total of 539 public parking spots in the area, i.e., $A=539$. We consider time slices of $1 \mathrm{~min}$ during a working day, i.e., $t=1 \mathrm{~min}$ and $T=1440$ $\min$. Based on the network properties, the travel distances $l_{n s / s}$ and $l /$ are both assumed to be uniformly distributed between 0.1 and $0.7 \mathrm{~km}$. The traffic properties are modeled after the macroscopic fundamental diagram of the city of Zurich (i.e., $v=12.5 \mathrm{~km} / \mathrm{h}$ ), based on (Ortigosa et al. (2014); Ambühl et al. (2017)).

The agent-based model MATSim (Waraich and Axhausen (2012)) was used to simulate the traffic demand and the initial conditions based on previous measurements. There is a total travel demand of 2687 trips spread between four different user groups (892/ 956/ 838/ 956 trips) in the network associated to different VOTs. These VOTs $\left(\right.$ VOT $^{1}=$ $29.9 \mathrm{CHF} / \mathrm{h} ; V O T^{2}=25.4 \mathrm{CHF} / \mathrm{h} ; V O T^{3}=25.8 \mathrm{CHF} / \mathrm{h} ; V O T^{4}=17.2 \mathrm{CHF} / \mathrm{h}$ ) are based on the estimated mean values for the VOT for car journeys in Switzerland (Axhausen et al. (2006)).

Fig. 4(b) shows the total traffic demand entering the network over all four user groups. $23 \%$ (618 trips) of the daily demand (i.e., $\beta^{i}=0.23, \forall i$ ) does not search for parking and can be considered as through-traffic or having dedicated parking spaces in the center, while 77\% (2069 trips) of the daily traffic searches for parking (Cao et al. (2017)). At the beginning of every working day 183 vehicles are already in the area, i.e., $N_{p}^{0}=183$ parking spaces are occupied. All other initial conditions are considered as zero, i.e., $N_{n s}^{0}=N_{s}^{0}=0$.

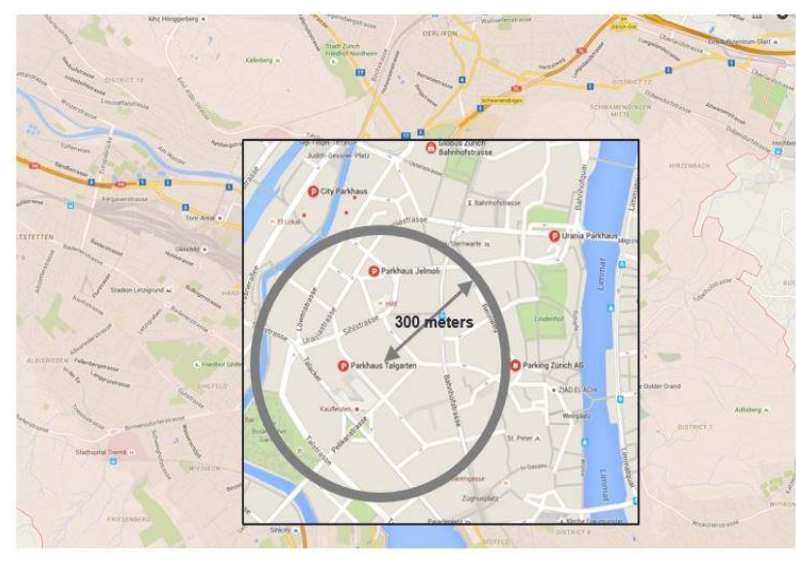

(a) Case study area in the city center of Zurich.

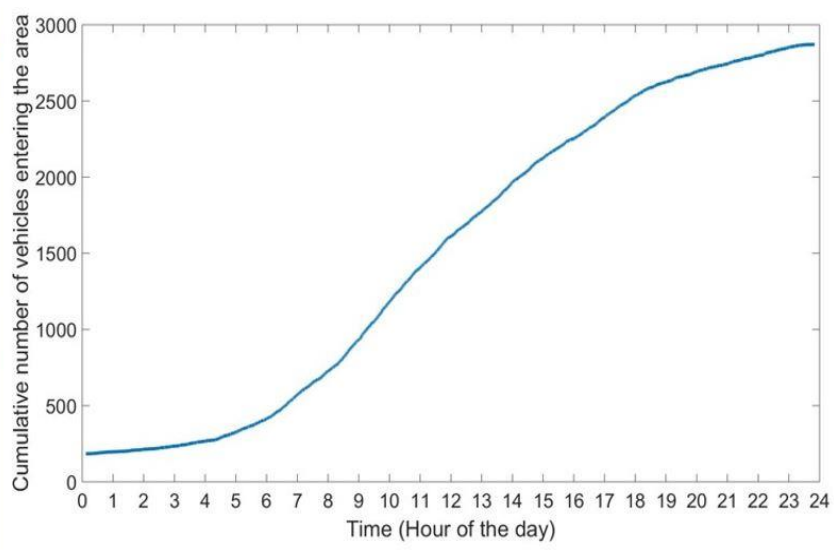

(b) Cumulative number of vehicles entering the area over one day.

Fig. 4. Case study area and traffic demand (Source: Cao et al. (2017)).

The distribution of parking durations is also determined using MATSim (Waraich and Axhausen (2012)). The resulting probability density function follows a gamma distribution with a shape parameter of 1.6 and a scale parameter of 142 (Cao et al. (2017)). The average parking duration is 227 minutes. The initial parking fee is set to $p^{0}=2.50 \mathrm{CHF}$ for all parking spots and the price per distance driven is $p_{\text {dist }}=0.3 \mathrm{CHF} / \mathrm{km}$. The maximum pricing change per time slice is set to $\Delta_{\max }=0.1 \mathrm{CHF} / \mathrm{min}$ and the predictive future parking fee is based on the past $\eta_{\text {pred }}=$ 10 time slices (i.e., last 10 minutes).

In the following section, we analyze the outputs with a focus on the revenue that can be collected with the aid of responsive parking fees, and its effects on the total searching time in the area.

\subsection{Parking pricing and traffic effects}

Is it possible to implement parking pricing without having a significant negative effect on either traffic performance 
or environmental conditions in the short term? In other words, is it possible to keep the total time and the total driven distance the same in the short-term when introducing parking pricing on the network? These are relevant questions for city councils or private agencies that we would like to analyze in this subsection.

For this case study, we compare the following pricing scenarios:

- Scenario (a): No parking pricing

- $\quad$ Scenario (b): Constant parking pricing (Parking pricing set to initial parking fee from scenarios (c) and (d), i.e., $2.50 \mathrm{CHF}$ for all time slices)

- Scenario (c): Occupancy-responsive parking pricing (Change in response to the parking occupancy)

- Scenario (d): Responsive parking pricing (Change in response to the parking occupancy and the number of searching vehicles)

All strategies result in a different parking pricing distribution over time with a different total revenue for the city. A total revenue of $5172 \mathrm{CHF}$ is reached in the constant pricing scenario (b) after the period of one day compared to no revenue in the free parking scenario (a) (Table 4).

Table 4. Total daily revenue (in CHF) for all scenarios.

\begin{tabular}{ll}
\hline Scenarios & Cumulative revenue (in CHF) \\
\hline Scenario (a): No parking pricing & 0 \\
Scenario (b): Constant parking pricing & 5172 \\
Scenario (c): Occupancy-responsive parking pricing & 7018 \\
Scenario (d): Responsive parking pricing & 9742 \\
\hline
\end{tabular}

The occupancy-responsive parking pricing strategy in scenario (c) uses the same methodology as our proposed pricing scheme in scenario (d). However, it is only dependent on the parking occupancy and there is no dependency on the number of searching vehicles on the network. Thus, Eq. (5) becomes $\Delta\left(A^{i}\right)^{-1}=\left(A^{i}\right)^{-1}-\left(A^{i-1}\right)^{-1}$ for all time slices. For our occupancy-responsive parking pricing scenario (c), we get the parking pricing output over time in Fig. 5 (a). This plot is obtained by grouping the pricing fees over 5 consecutive time slices, i.e., the parking price is updated every 5 minutes. In addition, the parking fee is rounded to the next $0.5 \mathrm{CHF}$ value to simplify the pricing structure ${ }^{1}$. Recall that the parking fee cannot decrease below its initial value of $2.5 \mathrm{CHF}$. This pricing structure reflects the parking occupancy over time. This occupancy rate reaches its peak of $6.5 \mathrm{CHF}$ at midday around the $12 \mathrm{hr}$ and the $14 \mathrm{hr}$. Since we consider the shopping area Jelmoli within the city of Zurich, this might be explained by the shop opening time and the workers' lunch break, i.e., around this time most parking spaces are occupied. This rate decreases until the parking fee changes back to its initial value at approximately $16 \mathrm{hrs}$. The total revenue obtained with this pricing strategy amounts to $7018 \mathrm{CHF}$ after the period of one day (Table 4).

\footnotetext{
${ }^{1}$ For real-time pricing schemes it might be interesting to investigate a dampening mechanism to reduce oscillations, but this is considered out-ofscope for now and can be analyzed in future studies.
} 


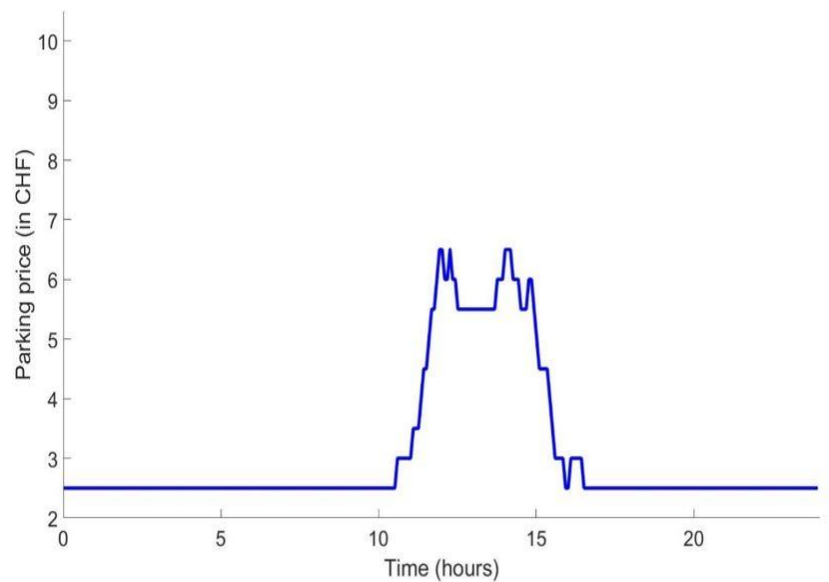

(a) Occupancy-responsive parking pricing (scenario (c)).

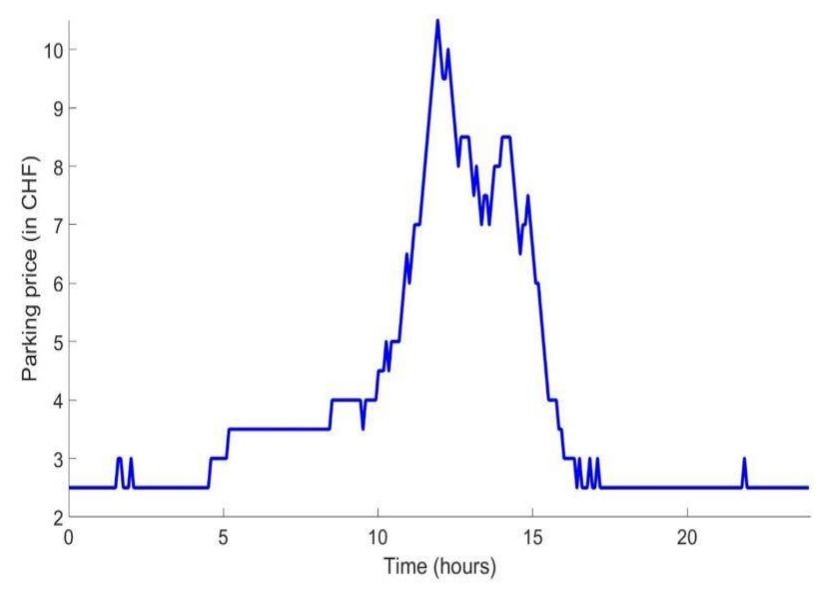

(b) Responsive parking pricing (scenario (d)).

Fig. 5. Responsive parking pricing (in CHF) over time (in hours) in scenarios (c) and (d).

For our responsive parking pricing scenario (d), we get the parking pricing output over time in Fig. 5(b). As in the previous case, this output is obtained by grouping the pricing fees over 5 consecutive time slices and rounding it to the next 0.5 CHF value. Additionally, the parking fee must remain $2.5 \mathrm{CHF}$ or higher. This parking pricing approach in Fig. 5(b) reflects the number of searching vehicles and available parking spaces on the network during the period of a working day. The pricing peak lasts approximately between the $10 \mathrm{hr}$ and the 15: $30 \mathrm{hr}$, i.e., around this time shops are open and, e.g., workers might drive there during their lunch break. The parking fee shows two peaks during this time period, the first peak reaches $10.5 \mathrm{CHF}$ at midday and the second pricing peak reaches $8.5 \mathrm{CHF}$ at approximately $14 \mathrm{hrs}$. During this period of time, there are more searching vehicles than available parking spaces in the area (i.e., the real-time demand is higher than the real-time supply) (Cao et al. (2017)). Scenario (d) leads to a total revenue of 9742 CHF over the period of one working day (Table 4).

All parking pricing scenarios lead to different revenues for the city. However, coming back to our initial question, all scenarios result in the same time and distance costs on the network (Table 5). Due to the optimization algorithm in Eq. (6) no vehicles decide for extra cruising on the network. Thus, we have shown that it is possible to implement parking pricing without having a negative effect on traffic performance nor environmental conditions. The free or constant parking fee in scenarios (a) and (b) lead to the fact that Eq. (3) is always fulfilled, such that the drivers decide to park at the first possible parking location. The parking fees in scenarios (c) and (d) are chosen to minimize the total cruising time on the network, i.e., the parking pricing should not encourage drivers to keep on searching for a better future alternative in terms of cost. The average value for all VOT considering all user groups $\frac{1}{K} \cdot \sum_{k=1}^{K} V_{O T}^{k}=0.41$ $\mathrm{CHF} / \mathrm{min}$ is used in Table 5 to determine the total time related costs.

Table 5. Average/Total time and driven distance in the network (for all scenarios).

\begin{tabular}{llllll}
\hline State & $\begin{array}{l}\text { Average time } \\
\text { per vehicle } \\
(\mathrm{min} / \mathrm{veh})\end{array}$ & $\begin{array}{l}\text { Total time } \\
(\mathrm{min})\end{array}$ & $\begin{array}{l}\text { Total costs } \\
\text { (converted } \\
\text { through VOT) }\end{array}$ & $\begin{array}{l}\text { Average driven } \\
\text { distance } \\
(\mathrm{km} / \mathrm{veh})\end{array}$ & $\begin{array}{l}\text { Total driven } \\
\text { distance } \\
(\mathrm{km})\end{array}$ \\
\hline Searching state & 3.14 & 7078 & 2902 & 0.65 & 1475 \\
Non-searching state & 4.43 & 9986 & 4094 & 0.92 & 2080 \\
\hline Total & 7.57 & 17064 & 6996 & 1.57 & 3555 \\
\hline
\end{tabular}

Our responsive parking pricing strategy in scenario (d) not only provides a feasible model that minimizes the total cruising time on the network, but it also leads to financial revenues that significantly exceed the revenues obtained in the other pricing scenarios. Having a dependency on the number of searching vehicles results in much higher parking fee values over time compared to scenario (c), plus a slightly different pricing pattern throughout the day. The total 
revenue in scenario (d) increases by $38.8 \%$ compared to scenario (c) and by $88.4 \%$ compared to scenario (b), such that the pricing strategy leads to significant improvements for city councils or private agencies in the area. In addition, the responsive parking fee in Fig. 5(b) reflects the parking search phenomenon as well as the parking occupancy rate, and does not have negative influences on traffic performance nor environmental conditions in the short-term.

\subsection{Impact of traffic demand and parking supply}

In this section, we investigate the impact of traffic demand and parking supply on our parking pricing model. Table 6 shows a comparison between the reference scenario (d) in section 4.2 and the responsive parking pricing scenarios with a $4 \%$ decrease or increase in the demand or the supply. As before, the average value for all VOT considering all user groups $\frac{1}{K} \cdot \sum_{k=1}^{K} V O T^{k}=0.41 \mathrm{CHF} / \mathrm{min}$ is used in Table 6 to determine the total time related costs.

Table 6 illustrates that the total revenue increases as soon as the traffic system gets more congested, i.e., the demand increases or the supply decreases. However, the total revenue is more sensitive to an increase in demand $(+29.1 \%)$ compared to a decrease in supply $(+23.6 \%)$, while the traffic performance and the environmental conditions are more sensitive to a decrease in supply. The average time per vehicle and the average driven distance in the searching-state illustrate this behaviour. The results for the non-searching-state do not show a high sensitivity towards an increase/decrease in supply nor in demand. This is not surprising, as the non-searching traffic is only indirectly affected by these changes. Both scenarios of decreasing the demand and increasing the supply lead to less cruising vehicles in the area and a reduction on revenue for the city. The average time and the average driven distance per vehicle show similar results for both scenarios, such that the traffic performance and the environmental conditions have the same sensitivity towards a decrease in demand and an increase in supply. The total revenue, however, is more sensitive to a decrease in demand $(-17 \%)$ compared to an increase in supply $(-13.3 \%)$. Overall, the total revenue is more sensitive to changes in demand compared to changes in supply.

Our macroscopic parking pricing model might result in meaningful advice to the city, e.g., when considering inquiries for reducing or creating new parking spaces or when considering a population growth/decline with an effect on traffic demand. Additionally, the model allows city officials to explore changes in the parking pricing scheme while trying to optimize different criteria (e.g., maximize revenues such that the area is not significantly congested, or minimize travel distance) in the network. 
Table 6. Comparison of reference scenario (d) to responsive parking pricing scenarios with a decrease/increase in demand and supply. Value within parenthesis represents the percentage change with respect to the reference scenario.

\begin{tabular}{|c|c|c|c|c|c|c|c|}
\hline & Scenarios & $\begin{array}{l}\text { Average time } \\
\text { per vehicle } \\
(\mathrm{min} / \mathrm{veh})\end{array}$ & $\begin{array}{l}\text { Total time } \\
(\mathrm{min})\end{array}$ & $\begin{array}{l}\text { Total costs } \\
\text { (converted } \\
\text { through VOT) }\end{array}$ & $\begin{array}{l}\text { Average } \\
\text { driven } \\
\text { distance } \\
(\mathrm{km} / \mathrm{veh})\end{array}$ & $\begin{array}{l}\text { Total driven } \\
\text { distance } \\
(\mathrm{km})\end{array}$ & Total revenue \\
\hline \multirow{5}{*}{ 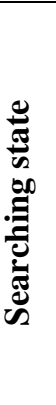 } & Scenario (d) & 3.14 & 7078 & 2902 & 0.65 & 1475 & \\
\hline & $\begin{array}{l}\text { Demand decrease } \\
(-4 \%)\end{array}$ & $\begin{array}{l}1.47 \\
(-53.2 \%)\end{array}$ & $\begin{array}{l}3181 \\
(-55.1 \%)\end{array}$ & $\begin{array}{l}1304 \\
(-55.1 \%)\end{array}$ & $\begin{array}{l}0.31 \\
(-52.3 \%)\end{array}$ & $\begin{array}{l}663 \\
(-55.1 \%)\end{array}$ & \\
\hline & $\begin{array}{l}\text { Demand increase } \\
(+4 \%)\end{array}$ & $\begin{array}{l}7.02 \\
(+123.6 \%)\end{array}$ & $\begin{array}{l}16395 \\
(+131.6 \%)\end{array}$ & $\begin{array}{l}6722 \\
(+131.6 \%)\end{array}$ & $\begin{array}{l}1.46 \\
(+124.6 \%)\end{array}$ & $\begin{array}{l}3416 \\
(+131.6 \%)\end{array}$ & \\
\hline & $\begin{array}{l}\text { Supply decrease } \\
(-4 \%)\end{array}$ & $\begin{array}{l}7.26 \\
(+131.2 \%)\end{array}$ & $\begin{array}{l}16348 \\
(+131 \%)\end{array}$ & $\begin{array}{l}6703 \\
(+131 \%)\end{array}$ & $\begin{array}{l}1.51 \\
(+132.3 \%)\end{array}$ & $\begin{array}{l}3406 \\
(+130.9 \%)\end{array}$ & \\
\hline & $\begin{array}{l}\text { Supply increase } \\
(+4 \%)\end{array}$ & $\begin{array}{l}1.47 \\
(-53.2 \%)\end{array}$ & $\begin{array}{l}3317 \\
(-53.1 \%)\end{array}$ & $\begin{array}{l}1360 \\
(-53.1 \%)\end{array}$ & $\begin{array}{l}0.31 \\
(-52.3 \%)\end{array}$ & $\begin{array}{l}691 \\
(-53.2 \%)\end{array}$ & \\
\hline \multirow{5}{*}{ 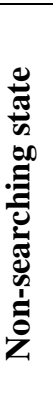 } & Scenario (d) & 4.43 & 9986 & 4094 & 0.92 & 2080 & \\
\hline & $\begin{array}{l}\text { Demand decrease } \\
(-4 \%)\end{array}$ & $\begin{array}{l}4.43 \\
(+0 \%)\end{array}$ & $\begin{array}{l}9607 \\
(-3.8 \%)\end{array}$ & $\begin{array}{l}3939 \\
(-3.8 \%)\end{array}$ & $\begin{array}{l}0.92 \\
(+0 \%)\end{array}$ & $\begin{array}{l}2001 \\
(-3.8 \%)\end{array}$ & \\
\hline & $\begin{array}{l}\text { Demand increase } \\
(+4 \%)\end{array}$ & $\begin{array}{l}4.44 \\
(+0.2 \%)\end{array}$ & $\begin{array}{l}10362 \\
(+3.8 \%)\end{array}$ & $\begin{array}{l}4248 \\
(+3.8 \%)\end{array}$ & $\begin{array}{l}0.92 \\
(+0 \%)\end{array}$ & $\begin{array}{l}2159 \\
(+3.8 \%)\end{array}$ & \\
\hline & $\begin{array}{l}\text { Supply decrease } \\
(-4 \%)\end{array}$ & $\begin{array}{l}4.43 \\
(+0 \%)\end{array}$ & $\begin{array}{l}9980 \\
(-0.1 \%)\end{array}$ & $\begin{array}{l}4092 \\
(-0.1 \%)\end{array}$ & $\begin{array}{l}0.92 \\
(+0 \%)\end{array}$ & $\begin{array}{l}2079 \\
(-0.05 \%)\end{array}$ & \\
\hline & $\begin{array}{l}\text { Supply increase } \\
(+4 \%)\end{array}$ & $\begin{array}{l}4.44 \\
(+0.2 \%)\end{array}$ & $\begin{array}{l}9989 \\
(+0.03 \%)\end{array}$ & $\begin{array}{l}4095 \\
(+0.03 \%)\end{array}$ & $\begin{array}{l}0.92 \\
(+0 \%)\end{array}$ & $\begin{array}{l}2081 \\
(+0.05 \%)\end{array}$ & \\
\hline \multirow{5}{*}{$\stackrel{5}{0}$} & Scenario (d) & 7.57 & 17064 & 6996 & 1.57 & 3555 & 9742 \\
\hline & $\begin{array}{l}\text { Demand decrease } \\
(-4 \%)\end{array}$ & $\begin{array}{l}5.9 \\
(-22.1 \%)\end{array}$ & $\begin{array}{l}12788 \\
(-25.1 \%)\end{array}$ & $\begin{array}{l}5243 \\
(-25.1 \%)\end{array}$ & $\begin{array}{l}1.23 \\
(-21.7 \%)\end{array}$ & $\begin{array}{l}2664 \\
(-25.1 \%)\end{array}$ & $\begin{array}{l}8084 \\
(-17 \%)\end{array}$ \\
\hline & $\begin{array}{l}\text { Demand increase } \\
(+4 \%)\end{array}$ & $\begin{array}{l}11.46 \\
(+51.4 \%)\end{array}$ & $\begin{array}{l}26757 \\
(+56.8 \%)\end{array}$ & $\begin{array}{l}10970 \\
(+56.8 \%)\end{array}$ & $\begin{array}{l}2.38 \\
(+51.6 \%)\end{array}$ & $\begin{array}{l}5575 \\
(+56.8 \%)\end{array}$ & $\begin{array}{l}12581 \\
(+29.1 \%)\end{array}$ \\
\hline & $\begin{array}{l}\text { Supply decrease } \\
(-4 \%)\end{array}$ & $\begin{array}{l}11.69 \\
(+54.4 \%)\end{array}$ & $\begin{array}{l}26328 \\
(+54.3 \%)\end{array}$ & $\begin{array}{l}10795 \\
(+54.3 \%)\end{array}$ & $\begin{array}{l}2.43 \\
(+54.8 \%)\end{array}$ & $\begin{array}{l}5485 \\
(+54.3 \%)\end{array}$ & $\begin{array}{l}12044 \\
(+23.6 \%)\end{array}$ \\
\hline & $\begin{array}{l}\text { Supply increase } \\
(+4 \%)\end{array}$ & $\begin{array}{l}5.91 \\
(-21.9 \%)\end{array}$ & $\begin{array}{l}13306 \\
(-22 \%)\end{array}$ & $\begin{array}{l}5455 \\
(-22 \%)\end{array}$ & $\begin{array}{l}1.23 \\
(-21.7 \%)\end{array}$ & $\begin{array}{l}2772 \\
(-22 \%)\end{array}$ & $\begin{array}{l}8450 \\
(-13.3 \%)\end{array}$ \\
\hline
\end{tabular}

\section{Conclusions}

In this study, we develop a dynamic macroscopic parking pricing model and analyze the interdependency between responsive parking pricing and searching-for-parking traffic. The model is integrated into an existing parking-statebased matrix to better model the real urban traffic and parking systems. The responsive pricing model is illustrated in a case study of an area within the city of Zurich, Switzerland. In addition, other three parking pricing scenarios are analyzed in this case study. These include a free, a constant, and an occupancy-responsive parking pricing scheme where the fee only changes in response to the parking occupancy.

The main contributions from this paper are summarized below.

- Our responsive pricing scheme takes the parking search phenomenon into consideration, by changing in response to the number of searching vehicles, compared to previous studies that only focus on the parking occupancy. This 
means that the parking fee also changes in response to the parking demand, in addition to changes in response to the parking supply.

- An optimization model is formulated to maximize the parking pricing revenue to the highest level, yet minimize the negative impacts on the traffic system (i.e., minimize total cruising time on the network). This is achieved as the model tries to guarantee that the cost of paying the current parking fee remains smaller than the cost of keep on searching to obtain a lower parking fee across multiple user groups with different VOTs. The vehicles' decision to park depends on multiple factors, including the predicted parking cost at future time, the costs of traveling from the current parking spot to another parking space associated with driving distance and VOT, and the penalty cost associated with the cruising time in past iterations.

- The model also provides a preliminary idea for city councils regarding an optimal parking pricing policy resulting in financial revenues while simultaneously minimizing the drivers' cruising time. The policy's impacts on the searching-for-parking traffic (cruising), the congestion in the network (traffic performance), the total driven distance (environmental conditions), and the revenue created by parking fees for the city are illustrated in a case study. In the short-term this parking pricing policy has neither significant negative influences on traffic performance nor environmental conditions, but it significantly increases the total revenue. This could lead to significant improvements for city councils or private agencies in the area. Notice that in the short-term the optimal parking fee might increase the revenue, but in the long-term it might deter drivers from driving into the city, potentially changing the demand. However, these long-term effects have not been studied here as they are considered out-of-scope in this paper.

- In comparison to microscopic models or agent-based simulation tools which are typically used when analyzing the interdependency between parking pricing and parking-caused traffic issues, the macroscopic model proposed here has several advantages. The whole framework is based on very limited data inputs, while most of the tools used nowadays to analyze parking pricing and parking-related traffic require a lot of detailed data that is hard to get. Our model corresponds to aggregated values at the network level over time and only needs some general inputs, including probability distributions, i.e., it saves on data collection efforts and reduces the computational costs significantly. Such efficiencies are especially useful for real-time control algorithms or when the data is scarce. Moreover, the model can be easily solved with a simple numerical solver such as Excel or Matlab without the use of complex simulation software. This is in part possible because we only have a few parameters, and all of them have a physical interpretation. Moreover, they can all be obtained from field data. In addition, there is no need to run the model many times in order to account for its stochasticity, as it is based on probability functions (i.e., the stochasticity is already implicit within the model formulations). Last but not least, the simpler form of the macroscopic model might provide additional insights that cannot be delivered by microscopic models (e.g., insights into the mathematical relation between traffic speeds and maximal parking pricing with respect to a minimal total cruising time on the network).

Overall, the potential of the proposed model is far beyond what we have illustrated in the case study. The pricing of off-street parking facilities can be modeled explicitly, such as the pricing of not uniformly distributed parking spaces over the network. In reality, vehicles could focus on parking possibilities in a central street or area of the network, while discarding other parking opportunities elsewhere. Future research could incorporate this nonhomogeneous environment (e.g., where both, the parking demand and supply are inhomogeneously distributed) by modeling different adjacent subnetworks, where parking decisions are made using the proposed macroscopic model based on the conditions of more than one subnetwork. Each subnetwork can have a different distribution of parking spaces and parking prices. How to connect these subnetworks to each other should then be carefully studied. Additionally, it could be possible to introduce different pricing alternatives. For example, we could include a traffic demand split with a fixed (low subsidized) parking fee in all garages and/or some of the on-street parking spaces. This can be motivated by, e.g., the subsidy from a company or the city for its employees or residents, respectively. The remaining portion of the demand could then be treated responsively as in this paper, reflecting the external costs for parking.

In summary, the proposed model, despite its simplicity, can be used to efficiently evaluate a dynamic responsive pricing scheme macroscopically. With the aid of limited aggregated data, this model can be used to investigate, how parking pricing can affect searching-for-parking traffic and traffic performance (e.g., average time searching for 
parking, and average distance driven); and how different traffic conditions (e.g., number of vehicles cruising for parking, and available parking spaces in the network) can affect the responsive parking pricing.

\section{Acknowledgements}

We would like to thank Mr. Milos Balac for providing access to relevant model input data.

\section{References}

Ambühl, L., Loder, A., Menendez, M., Axhausen, K.W., 2017. Empirical Macroscopic Fundamental Diagrams: Insights from loop detector and floating car data, Proceedings of the 96th Transportation Research Board Annual Meeting (TRB), Washington D.C., January 2017.

Anderson, S., de Palma, A., 2004. The economics of pricing parking. Journal of Urban Economics 55.1, pp. 1-20.

Arnott, R., de Palma, A., Lindsey, C.R., 1991. A temporal and spatial equilibrium analysis of commuter parking. Journal of Public Economics 45.3, pp. 301-335.

Arnott, R., Rowse, J., 2009. Downtown parking in auto city. Region 39, pp. 1-14.

Auchincloss, A.H., Weinberger, R., Aytur, S., Namba, A., Ricchezza, A., 2015. Public Parking Fees and Fines: A Survey of U.S. Cities. Public Works Management \& Policy, Vol. 20 (1), pp. 49-59.

Axhausen, K.W., König, A., Abay, G., Bates, J.J., Bierlaire, M., 2006. Swiss value of travel time savings. ETH, Eidgenössische Technische Hochschule Zürich, IVT, Institut für Verkehrsplanung und Transportsysteme.

Ayala, D., Wolfson, O., Xu, B., Dasgupta, B., Lin, J., 2012. Pricing of parking for congestion reduction. Proceedings of the 20th ACM SIGSPATIAL International Conference on Advances in Geographic Information Systems (ACM GIS), Redondo Beach, CA.

Bianco, M., 2000. Effective Transportation Demand Management: The Results of Combining Parking Pricing, Transit Incentives, and Transportation Management in a Commercial District of Portland, Oregon, Transportation Research Board - 79th Annual Meeting, Washington, D.C.

Cao, J., 2016. Effects of Parking on Urban Traffic Performance, Ph.D. Dissertation No. 23527, Eidgenössische Technische Hochschule Zürich, IVT, Institute for Transport Planning and Systems.

Cao, J., Menendez, M., 2013. Methodology to evaluate cost and accuracy of parking patrol surveys. Transportation Research Record 2359, pp. 19.

Cao, J., Menendez, M., 2015. System dynamics of urban traffic based on its parking-related-states. Transportation Research B, 81 (3), pp. $718-736$.

Cao, J., Menendez, M., Waraich, R., 2017. Impacts of the urban parking system on cruising traffic and policy development: The case of Zurich downtown area, Switzerland. Submitted to Transportation.

Daganzo, C.F., 2011. On the macroscopic stability of freeway traffic. Transportation Research Part B: Methodological, 45 (2011), pp. $782-788$.

Daganzo, C.F., Gayah, V.V., Gonzales, E.J., 2011. Macroscopic relations of urban traffic variables: Bifurcations, multivaluedness and instability. Transportation Research Part B: Methodological, 45 (2011), pp. 278-288.

Gayah, V.V., Daganzo, C.F., 2011. Effects of Turning Maneuvers and Route Choice on a Simple Network. Transportation Research Record: Journal of the Transportation Research Board, 2249 (2011), pp. 15-19.

Geroliminis, N., 2009. Dynamics of peak hour and effect of parking for congested cities. In: Proc. of the 88th Annual Meeting of Transportation Research Board, Washington D.C., USA.

Geroliminis, N., 2015. Cruising-for-parking in congested cities with an MFD representation. Economics of Transportation 4 (3), pp. 156-165.

Lautso, K., 1981. Mathematical relationships among parking characteristics and revising and reduction methods of parking field survey information. Transportation Research Part B 15B, pp. 73-83.

Lei, C., Ouyang, Y., 2017. Dynamic pricing and reservation for intelligent urban parking management. Transportation Research Part C: Emerging Technologies, 77, pp. 226-244.

Mackowski, D., Bai, Y., Ouyang, Y., 2015. Parking Space Management via Dynamic Performance-Based Pricing. Transportation Research Procedia, Volume 7, pp. 170-191.

Ortigosa, J., Menendez, M., Tapia, H., 2014. Study on the number and location of measurement points for an MFD perimeter control scheme: a case study of Zurich, EURO Journal on Transportation and Logistics, 3 (3), pp. 245-266.

Qian, Z.S., Rajagopala, R., 2013. Optimal parking pricing in general networks with provision of occupancy information. Procedia-Social and Behavioral Sciences, 80, pp. 1-26.

Qian, Z.S., Rajagopal, R., 2014. Optimal occupancy-driven parking pricing under demand uncertainties and traveler heterogeneity: a stochastic control approach. Transportation Research Part B: Methodological, 67, pp. 144-165.

Qian, Z.S., Rajagopal, R., 2015. Optimal dynamic pricing for morning commute parking. Transportmetrica A: Transport Science, 11, pp. $291-316$.

Richardson, A.J., 1974. An Improved Parking Duration Study. Australian Road Research Board Conference, vol. 7.

SFpark, San Francisco County Transportation Authority, 2009. SF-CHAMP Base OD. Available at: http://www.sfcta.org/downloads/ serviceBureau/. Accessed on August 31, 2015.

Van Nieuwkoop, R.H., 2014. Transportation Networks and Economic Equilibrium, Essay: A traffic equilibrium model with paid-parking search. $\mathrm{Ph} . D$. Dissertation, Eidgenössische Technische Hochschule Zürich, IVT, Institute for Transport Planning and Systems.

Wang, H., Meng, Q., Zhang, X., 2015. Optimal Parking Pricing in Many-to-One Park-and-Ride Network with Parking Space Constraints. Transportation Research Record Journal of the Transportation Research Board 2498. 
Waraich R., Axhausen K.W., 2012. Agent-Based Parking Choice Model. Transportation Research Record: Journal of the Transportation Research Board, Volume 2319, pp. 39-46, DOI: 10.3141/2319-05.

Wardrop, J.G., 1952. Some Theoretical Aspects of Road Traffic Research. Proceedings of the Institute of Civil Engineers, Part II, pp. $325-378$.

Zhang, X., Van Wee, G.P., 2011. Efficiency Comparison of Various Parking Charge Schemes Considering Daily Travel Cost in a Linear City. European Journal of Transport and Infrastructure Research 11 (2), pp. 234-255.

Zheng, N., Geroliminis, N., 2016. Modeling and optimization of multimodal urban networks with limited parking and dynamic pricing. Transportation Research Part B: Methodological, 83, pp. 36-58. 